\title{
Use of theragnostic markers to select drugs for phase II/III trials for Alzheimer disease
}

\author{
Henrik Zetterberg*, Niklas Mattsson, Kaj Blennow and Bob Olsson
}

\begin{abstract}
In a slowly progressive disorder like Alzheimer disease, evaluation of the clinical effect of novel drug candidates requires large numbers of patients and extended treatment periods. Current cell- and animalbased disease models of Alzheimer disease are poor at predicting a positive treatment response in patients. To help bridge the gap between disease models and large and costly clinical trials with high failure rates, biomarkers for the intended biochemical drug effect may be of value. Such biomarkers may be called 'theragnostic.' Here, we review the literature addressing the prospective value of these biomarkers.
\end{abstract}

\section{Background}

Three decades of multidisciplinary research have resulted in detailed knowledge of the molecular pathogenesis of Alzheimer disease (AD) [1]. We know that the symptoms of $\mathrm{AD}$ are caused by synaptic dysfunction and neuronal death in the areas of the brain that are involved in memory consolidation and other cognitive functions [1]. This neurodegeneration is firmly associated with aggregation of the 40- to 42-amino acid amyloid beta $(A \beta)$ peptide into senile plaques, phosphorylation and aggregation of tau proteins that form neurofibrillary tangles, and microglial activation that may be a protective response or contribute to the neuronal dysfunction and damage [2]. The relative importance of these processes to the clinical presentation of the disease remains uncertain.

Clinical trials of novel anti-AD drugs face at least two major challenges. First, the new types of drug candidates that attack basic disease processes are likely to be most effective in early stages of the disease, before neuronal

\footnotetext{
*Correspondence: henrik.zetterberg@gu.se
}

Department of Psychiatry and Neurochemistry, Institute of Neuroscience and Physiology, Sahlgrenska Academy at University of Gothenburg, S-431 80 Mölndal, Sweden degeneration has become too widespread and severe [3]. However, clinical methods that recognize early AD are lacking. Second, the drug candidates may slow down the degenerative process without having any immediate and easily recognizable symptomatic effect [4]. This makes evaluation of the drug effect difficult. Theragnostic biomarkers (that is, biomarkers that detect and monitor biochemical effects of the drug) may help solve some of these problems. Here, we review three pathological processes that are thought to be involved in the complex surge of AD - namely the amyloid cascade, abnormal tau phosphorylation, and microglial activation with neuroinflammation - and the currently available biomarkers thought to reflect them (Figure 1).

\section{Core biomarkers of Alzheimer disease}

It is well established that cerebrospinal fluid (CSF) levels of total tau (T-tau), phospho-tau (P-tau), and the 42-amino acid fragment of $A \beta$ (A $\beta 42)$ reflect core elements of the $\mathrm{AD}$ process [3]. T-tau is a marker of cortical axonal degeneration and disease activity [5-7]. P-tau reflects neurofibrillary pathology $[8,9]$. A $\beta 42$ is a marker of plaque pathology [9-12]. Together, these biomarkers identify $\mathrm{AD}$ and predict $\mathrm{AD}$ in mild cognitive impairment $(\mathrm{MCI})$ with a sensitivity and specificity of $75 \%$ to $95 \%$ [3]. The predictive power is, however, suboptimal in general populations as compared with $\mathrm{MCI}$ cohorts because of the lower prevalence of incipient $\mathrm{AD}$ in this group [13]. Plasma biomarkers reflective of pathophysiological changes in the $\mathrm{AD}$ brain are highly warranted, the subject of intense research, but unfortunately still lacking [3].

\section{Drug targets \\ Amyloid}

Experimental data, as well as longitudinal studies in humans, suggest that certain forms of $A \beta$ may act as initiators in the disease process with potent toxic effects at the synaptic level [2]. Based on this knowledge, novel treatments aimed at inhibiting $A \beta$ toxicity have been developed and are being tested in patients [14]. These include secretase inhibitors and modulators that affect the production of $A \beta$ from amyloid precursor protein (APP), immunotherapy aimed at increasing the clearance 


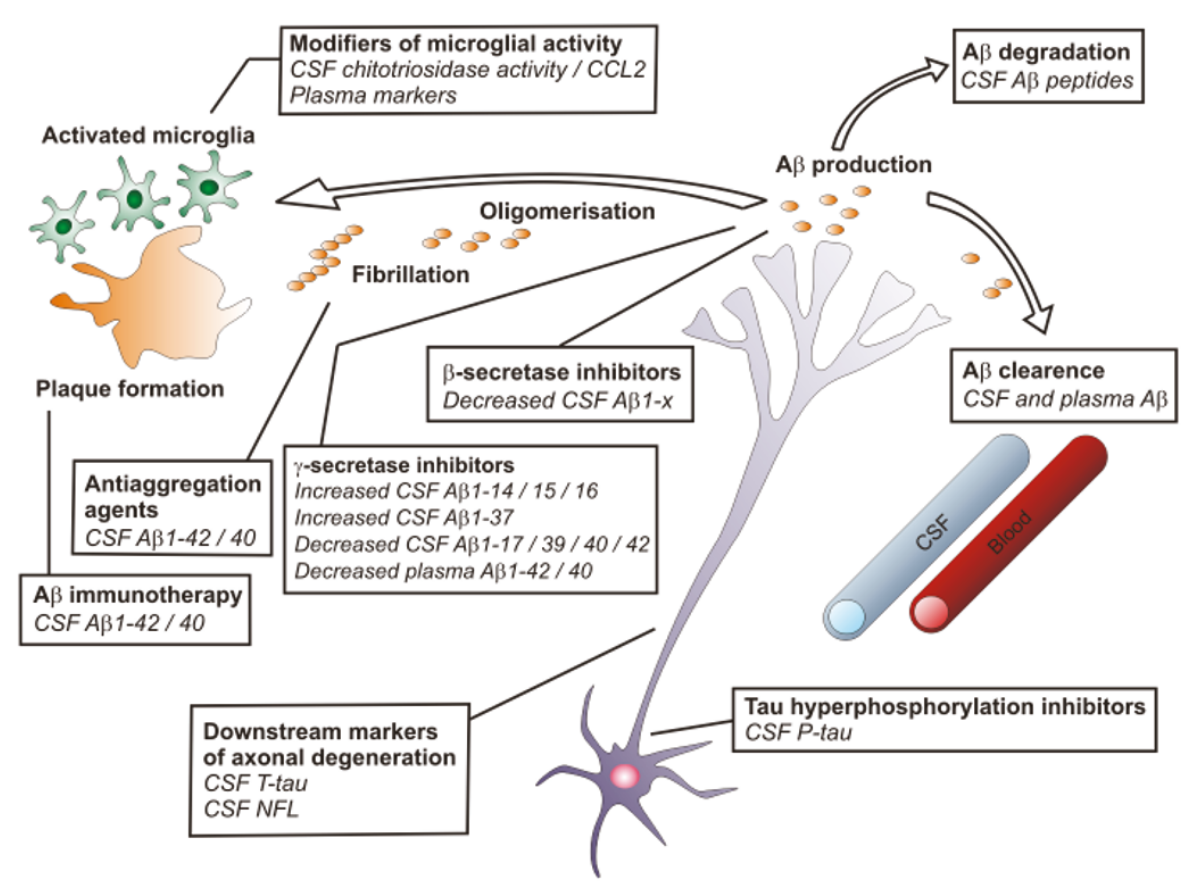

Figure 1. Summary of candidate theragnostic biomarkers that reflect key drug targets in the Alzheimer disease (AD) process. Betasecretase inhibitors should reduce cerebrospinal fluid (CSF) levels of amyloid beta (A $\beta$ ) isoforms starting at the first amino acid in the $A \beta$ sequence (A $\beta 1-X)$. Gamma-secretase inhibitors should reduce $A \beta 1-40$ and $A \beta 1-42$ and increase $A \beta 1-14, A \beta 1-15$, and $A \beta 1-16$. Both $A \beta$ immunotherapy and anti-aggregation agents might be monitored by CSF levels of $A \beta 1-40$ and $A \beta 1-42$. Therapy-induced $A \beta$ degradation might be monitored by CSF levels of different A $\beta$ peptides, depending on the proteolytic pathway used for degradation. $A \beta$ efflux from the brain to the blood might be monitored by measurement of A $\mathrm{B}$ in CSF and plasma. Inflammatory markers in plasma and CSF as well as CSF levels of CCL2 and chitotriosidase activity are putative markers of microglial activity and may change in response to treatments that influence microglial activity. Treatment with tau hyperphosphorylation inhibitors might be monitored with CSF phospho-tau (P-tau) levels. Downstream effects on axonal degeneration from disease-modifying treatments could be monitored by using the axonal damage markers CSF total tau (T-tau) and neurofilament light protein (NFL).

of $A \beta$ from the brain, and $A \beta$ aggregation inhibitors that should prevent pathological build-up of the peptide in the brain [14].

Tau

Among the typical brain lesions in $\mathrm{AD}$ are neurofibrillary tangles that consist of abnormally phosphorylated forms of the microtubule-stabilizing protein tau [15]. Tau expression is high in non-myelinated cortical axons, especially in the regions of the brain (such as the limbic cortex, including the hippocampus) which are involved in memory consolidation [16]. Hyperphosphorylation of tau causes the protein to detach from the microtubules and destabilizes the axons [17]. This process promotes axonal and synaptic plasticity in the developing brain [17] but may be pathological in the adult brain and specifically related to a group of disorders referred to as tauopathies; this group includes $\mathrm{AD}$ and some forms of frontotemporal dementia [15]. Inhibiting tau phosphorylation or aggregation has been considered a promising strategy to slow down the neurodegeneration in AD. Drug candidates intervening in tau-related disease processes (for example, inhibitors of the tau kinase GSK3 $\beta$ and tau aggregation inhibitors) exist but are still in an early phase of development [14].

\section{Microglial activation}

Microglia are the resident immune cells of the central nervous system (CNS) [18] and are macrophages of myeloid lineage and invade the CNS during embryogenesis. These innate immune cells perform the majority of the immunological surveillance in the CNS. However, in certain conditions such as multiple sclerosis or neuroborreliosis, infiltration of $\mathrm{T}$ cells but also $\mathrm{B}$ cells into the CNS occurs. Microglia are usually in a resting state but at any time may become activated in response to infection or injury [18]. The key question of microglia in $\mathrm{AD}$ is whether the inflammation mediated via microglia is beneficial or not. The capability of microglia to release reactive oxygen species, nitric oxide, interleukin-1-beta (IL-1 $\beta$ ), and tumor necrosis factor-alpha (TNF $\alpha$ ) is beneficial in response to invading pathogens. However, these compounds are also neurotoxic and collateral damage to neurons is frequent during infections. The same may occur in $\mathrm{AD}$ because plaques function as immunological triggers for the activation and recruitment of microglia, which may result 
in neuron loss [19]. On the other hand, microglia have been shown to clear deposits of $A \beta$ through the Toll-like receptor 4 (TLR4), and AD mice with a defective TLR4 have increased deposits of $A \beta[20]$.

\section{Other drug targets}

Besides the three targets mentioned above, several other approaches are aimed at improving neural transmission and memory consolidation in AD. These include nerve growth factor gene therapy, stimulation of nicotinergic acetylcholine receptors by varenicline, protein kinase $\mathrm{C}$ activation by bryostatin 1, and many more [21]. Theragnostic biomarkers for each of these drugs may be different from those reviewed below and are specifically related to the mode of action of the drug.

\section{Theragnostic biomarkers General issues}

Theragnostic markers have accelerated the development of treatments in some types of cancer, HIV infection, atherosclerosis, and multiple sclerosis, and cancerspecific fusion transcripts or mutations, viral load, plasma levels of low-density lipoprotein cholesterol, and brain MRI (magnetic resonance imaging) white matter lesion burden, respectively, have been used to ascertain that the drug candidate is beneficial [22]. These examples indicate that theragnostic markers may be useful in evaluating novel therapeutics also in AD. Furthermore, such studies may help to bridge the gap between animal studies that are poor at predicting treatment success in humans and large clinical trials [1]. Sometimes, these types of biomarkers are referred to as surrogate markers of pathogenic processes. However, the term surrogate marker often indicates a marker that is (i) a validated substitute for a clinically meaningful endpoint and (ii) expected to predict the effect of therapy $[23,24]$. This definition goes beyond a mere correlation between a laboratory measurement and a clinical outcome or a pathogenic process since a fully validated surrogate marker also requires proof that intervention on the surrogate marker predicts the effect on the clinical outcome [25]. If applied in full by regulatory authorities, very few biomarkers in medicine live up to these requirements, which may obstruct implementation of surrogate biomarkers in large-scale clinical trials. However, this circumstance does not hinder the use of non-validated surrogate markers when deciding upon the most promising drug candidates in early stages of drug development. Rather, this approach is advocated by the US Food and Drug Administration [26].

\section{Are they useful?}

To date, only preliminary reports suggest that CSF biomarkers may be useful in detecting and monitoring biochemical effects of novel drugs against AD. With regard to biomarkers for amyloid pathology, the many factors that influence steady-state levels of A $\beta$ in CSF (production, aggregation, enzymatic clearance, and bidirectional transport across the blood-brain barrier) make it difficult to predict what different amyloidtargeting treatment paradigms might do to CSF A $\beta$ concentrations. In fact, any treatment-induced change to an amyloid-related biomarker which is informative with respect to clinical outcome would be a major step forward. So far, data from animal studies show that $\gamma$-secretase inhibitor treatment results in a reduction in cortical, CSF, and plasma levels of $A \beta[27,28]$. Similarly, treatment of monkeys with a BACE1 inhibitor reduced the CSF levels of $A \beta 42, \quad A \beta 40$, and $\beta$-sAPP [29]. Other promising biomarkers that are closely linked to the amyloidogenic process in AD are CSF BACE1 (the major $\beta$-secretase) concentration and activity, CSF levels of $\alpha$ - and $\beta$-cleaved soluble APP, and A $\beta$ oligomers [30-32]. These biomarkers appear to provide information of limited diagnostic usefulness but may turn out to be important for identifying treatment effects of drugs that are meant to inhibit $\beta$ secretase or break up amyloid aggregates.

In patients with $A D$, it is uncertain how CSF $A \beta 42$ may respond to treatment with efficacious anti-A $\beta$ drugs. A phase IIa study of the $A \beta$ clearance-enhancing compound PBT2 showed a significant dose-dependent reduction in CSF A $\beta 42$ levels during treatment [33]. Data from a clinical study on the amyloid-targeting drug phenserine also showed changes in CSF A $\beta$ levels in response to treatment [34]. However, in the interrupted phase IIa AN1792 trial of active immunization against $A \beta$, no significant treatment effect on CSF A $\beta 42$ was found [35]. A clinical study on $\gamma$ secretase inhibitor treatment also failed to detect any effect on CSF A 42 levels [36]. Nevertheless, when the effect of this drug on $A \beta$ production rate by the use of a stable isotope-labeling kinetic technique was evaluated, a clear inhibitory effect of $\gamma$-secretase inhibition on $A \beta$ production was identified [37]. Recent data show that shorter $A \beta$ peptides in CSF - namely $A \beta 1-14, A \beta 1-15$, and $A \beta 1-16$ represent a novel APP-processing pathway [38] that is upregulated in a dose-dependent manner in response to $\gamma$ secretase inhibition [39].

Given longitudinal studies of conditions involving acute neuronal injury [40] and data from the interrupted phase IIa AN1792 trial [35], T-tau should decrease toward normal levels if a treatment is successful in inhibiting the neurodegenerative process in $\mathrm{AD}$. The same may be expected for P-tau, as suggested by two recent pilot studies on memantine $[41,42]$.

Currently, there are no established CSF biomarkers for microglial activation which could be used as theragnostic markers in trials aimed at inhibiting, boosting, or modulating microglial activity in $\mathrm{AD}$. Chemokine (C-C motif) 
ligand 2 (CCL2) (also called monocyte chemoattractant protein-1, or MCP-1) and chitotriosidase are firmly associated with macrophage activation in the periphery $[43,44]$ and may be considered promising markers of microglial activation in the CNS, but studies in relation to $\mathrm{AD}$ are scarce [45]. However, several biomarkers for general inflammation exist. Pilot studies showed increased CSF levels of transforming growth factor-beta (TGF $\beta)$ in $\mathrm{AD}$ as compared with controls [46,47]; this result was recently confirmed in a meta-analysis of cytokines in $\mathrm{AD}$ [48]. Other classical markers such as IL-1 $\beta$, IL-6, and TNF $\alpha$ were not altered in the CSF of patients with $\mathrm{AD}$. The plasma levels of several cytokines such as IL-1 $\beta$, IL-6, IL-12, IL-18, TNF $\alpha$, and TGF $\beta$ - but not IL-4, IL-8, IL-10, interferon- $\gamma$, or C-reactive protein were increased in AD. Together, these data argue for an inflammatory component in AD. However, the results of anti-inflammatory therapy in $\mathrm{AD}$ have been contradictory [49]. As explained above, the link between inflammation and other core disease processes in $\mathrm{AD}$ remains elusive.

\section{Concluding remarks}

Theoretical reasoning suggests that theragnostic biomarkers could play a major role in drug development against $\mathrm{AD}$, but, admittedly, the body of literature supporting this view is limited at present. We know quite a lot about central pathogenic features of the disease, and several biomarkers that monitor these features exist. A number of phase 0-I clinical trials indicating small but statistically significant effects on theragnostic biomarkers, mostly in relation to axonal integrity and amyloid pathology, have been published. Interpreting these biomarker results is, however, complicated by the fact that none of the studies was designed to detect clinical effects. This circumstance precludes analyses of whether the patients with biomarker changes imposed by the treatment were those with the clearest clinical benefit.

The recent interruption of the phase III trials (IDENTITY [Interrupting Alzheimer's Dementia by Evaluating Treatment of Amyloid Pathology] and IDENTITY-2) of the $\gamma$-secretase inhibitor semagacestat (LY450139) (Eli Lilly and Company, Indianapolis, IN, USA) may be considered a blow to the field of theragnostic biomarkers. Despite compelling evidence in cell and animal models, as well as plasma $A \beta$ data [36] and $A \beta$ turnover rates [37] in humans, suggesting that the compound reduces $A \beta$ production, cognition declined faster in the treatment arms compared with placebo. In our view, these data should spur us to continue developing more biomarkers for APP- and A $\beta$ processing for other desired drug effects such as improvement of neural transmission as well as for undesired effects (for example, inhibition of Notch
This article is part of a review series on Failed clinical trials. Other articles in the series can be found online at http://alzres.com/series/ failedtrials

signaling). For another recently failed trial (tarenflurbil, which is supposed to act as a $\gamma$-secretase modulator), there were plenty of biomarker data suggesting that the drug did not hit its target in the human brain [50]. These data could have curbed the enthusiasm to move to phase III and thus saved a lot of money.

Several other clinical trials on disease-modifying drug candidates which include biomarkers as readouts are currently ongoing. These trials will provide more evidence on whether biomarkers will be useful as tools to select the most promising drug candidates for phase II/ III trials for $\mathrm{AD}$.

\section{Abbreviations}

$A \beta$, amyloid beta; $A \beta 42,42$-amino acid fragment of amyloid beta; $A D$, Alzheimer disease; APP, amyloid precursor protein; CNS, central nervous system; CSF, cerebrospinal fluid; IDENTITY, Interrupting Alzheimer's Dementia by Evaluating Treatment of Amyloid Pathology; IL, interleukin; MCI, mild cognitive impairment; P-tau, phospho-tau; T-tau, total tau; TGF $\beta$, transforming growth factor-beta; TLR4, Toll-like receptor 4; TNFa, tumor necrosis factor-alpha.

\section{Competing interests}

$\mathrm{HZ}$ has served on an advisory board for GlaxoSmithKline (Uxbridge, Middlesex, UK). KB has served on an advisory board for Innogenetics (Gent, Belgium). The other authors declare that they have no competing interests.

\section{Acknowledgments}

Work in the authors' laboratories is supported by the Royal Swedish Academy of Sciences, the Swedish Research Council, and the Alzheimer's Association.

Published: 30 November 2010

\section{References}

1. Blennow K, de Leon MJ, Zetterberg H: Alzheimer's disease. Lancet 2006 , 368:387-403.

2. Querfurth HW, LaFerla FM: Alzheimer's disease. N Engl J Med 2010, 362:329-344.

3. Blennow $\mathrm{K}$, Hampel $\mathrm{H}$, Weiner M, Zetterberg $\mathrm{H}$ : Cerebrospinal fluid and plasma biomarkers in Alzheimer disease. Nat Rev Neurol 2010, 6:131-144.

4. Siemers ER: How can we recognize 'disease modification' effects? J Nutr Health Aging 2009, 13:341-343.

5. Samgard K, Zetterberg H, Blennow K, Hansson O, Minthon L, Londos E: Cerebrospinal fluid total tau as a marker of Alzheimer's disease intensity. Int J Geriatr Psychiatry 2010, 25:403-410.

6. Blom ES, Giedraitis V, Zetterberg H, Fukumoto H, Blennow K, Hyman BT, Irizarry MC, Wahlund LO, Lannfelt L, Ingelsson M: Rapid progression from mild cognitive impairment to Alzheimer's disease in subjects with elevated levels of tau in cerebrospinal fluid and the APOE epsilon4/ epsilon4 genotype. Dement Geriatr Cogn Disord 2009, 27:458-464.

7. Buerger K, Ewers M, Andreasen N, Zinkowski R, Ishiguro K, Vanmechelen E, Teipel SJ, Graz C, Blennow K, Hampel H: Phosphorylated tau predicts rate of cognitive decline in $\mathrm{MCl}$ subjects: a comparative CSF study. Neurology 2005, 65:1502-1503.

8. Buerger K, Ewers M, Pirttilä T, Zinkowski R, Alafuzoff I, Teipel SJ, DeBernardis J Kerkman D, McCulloch C, Soininen H, Hampel H: CSF phosphorylated tau protein correlates with neocortical neurofibrillary pathology in Alzheimer's disease. Brain 2006, 129:3035-3041.

9. Tapiola T, Alafuzoff I, Herukka SK, Parkkinen L, Hartikainen P, Soininen H, Pirttila T: Cerebrospinal fluid \{beta\}-amyloid 42 and tau proteins as biomarkers of Alzheimer-type pathologic changes in the brain. Arch Neurol 2009, 66:382-389. 
10. Fagan AM, Mintun MA, Mach RH, Lee SY, Dence CS, Shah AR, LaRossa GN, Spinner ML, Klunk WE, Mathis CA, DeKosky ST, Morris JC, Holtzman DM: Inverse relation between in vivo amyloid imaging load and cerebrospinal fluid Abeta42 in humans. Ann Neurol 2006, 59:512-519.

11. Forsberg A, Engler $H$, Almkvist $O$, Blomquist $G$, Hagman $G$, Wall A, Ringheim A, Langstrom $B$, Nordberg A: PET imaging of amyloid deposition in patients with mild cognitive impairment. Neurobiol Aging 2008, 29:1456-1465.

12. Strozyk D, Blennow K, White LR, Launer LJ: CSF Abeta 42 levels correlate with amyloid-neuropathology in a population-based autopsy study. Neurology 2003, 60:652-656.

13. Mattsson $\mathrm{N}$, Zetterberg $\mathrm{H}$ : Future screening for incipient Alzheimer's disease - the influence of prevalence on test performance. Eur Neuro/ 2009, 62:200-203.

14. Panza F, Solfrizzi V, Frisardi V, Imbimbo BP, Capurso C, D'Introno A, Colacicco AM, Seripa D, Vendemiale G, Capurso A, Pilotto A: Beyond the neurotransmitter-focused approach in treating Alzheimer's disease: drugs targeting beta-amyloid and tau protein. Aging Clin Exp Res 2009, 21:386-406.

15. Hampel H, Blennow K, Shaw LM, Hoessler YC, Zetterberg H, Trojanowski JQ: Total and phosphorylated tau protein as biological markers of Alzheimer's disease. Exp Gerontol 2010, 45:30-40.

16. Trojanowski JQ, Schuck T, Schmidt ML, Lee VM: Distribution of tau proteins in the normal human central and peripheral nervous system. $J$ Histochem Cytochem 1989, 37:209-215.

17. Lovestone $\mathrm{S}$, Reynolds $\mathrm{CH}$ : The phosphorylation of tau: a critical stage in neurodevelopment and neurodegenerative processes. Neuroscience 1997, 78:309-324.

18. Graeber MB: Changing face of microglia. Science 2010, 330:783-788.

19. Fuhrmann M, Bittner T, Jung CK, Burgold S, Page RM, Mitteregger G, Haass C, LaFerla FM, Kretzschmar H, Herms J: Microglial Cx3cr1 knockout prevents neuron loss in a mouse model of Alzheimer's disease. Nat Neurosci 2010, 13:411-413

20. Tahara K, Kim HD, Jin JJ, Maxwell JA, Li L, Fukuchi K: Role of toll-like receptor signalling in Abeta uptake and clearance. Brain 2006, 129:3006-3019.

21. ClinicalTrials.gov homepage [http://clinicaltrials.gov].

22. Hurko O: The uses of biomarkers in drug development. Ann N Y Acad SCi 2009, 1180:1-10.

23. Temple R: Are surrogate markers adequate to assess cardiovascular disease drugs? JAMA 1999, 282:790-795.

24. Biomarkers Definitions Working Group: Biomarkers and surrogate endpoints: preferred definitions and conceptual framework. Clin Pharmacol Ther 2001, 69:89-95.

25. Siemers E, DeMattos RB, May PC, Dean RA: Role of biochemical Alzheimer's disease biomarkers as end points in clinical trials. Biomark Med 2010, 4:81-89.

26. Katz R: Biomarkers and surrogate markers: an FDA perspective. NeuroRx 2004, 1:189-195.

27. Anderson JJ, Holtz G, Baskin PP, Turner M, Rowe B, Wang B, Kounnas MZ, Lamb BT, Barten D, Felsenstein K, McDonald I, Srinivasan K, Munoz B, Wagner SL: Reductions in beta-amyloid concentrations in vivo by the gammasecretase inhibitors BMS-289948 and BMS-299897. Biochem Pharmacol 2005, 69:689-698.

28. Lanz TA, Hosley JD, Adams WJ, Merchant KM: Studies of Abeta pharmacodynamics in the brain, cerebrospinal fluid, and plasma in young (plaque-free) Tg2576 mice using the gamma-secretase inhibitor N2-[(2S)2-(3,5-difluorophenyl)-2-hydroxyethanoyl]-N1-[(7S)-5-methyl-6-oxo-6,7dihydro-5H-dibenzo[b,d]azepin-7-yl]-L-alaninamide (LY-411575). J Pharmacol Exp Ther 2004, 309:49-55.

29. Sankaranarayanan S, Holahan MA, Colussi D, Crouthamel MC, Devanarayan V, Ellis J, Espeseth A, Gates AT, Graham SL, Gregro AR, Hazuda D, Hochman JH, Holloway K, Jin L, Kahana J, Lai MT, Lineberger J, McGaughey G, Moore KP, Nantermet P, Pietrak B, Price EA, Rajapakse H, Stauffer S, Steinbeiser MA, Seabrook G, Selnick HG, Shi XP, Stanton MG, Swestock J, et al.: First demonstration of cerebrospinal fluid and plasma $A$ beta lowering with oral administration of a beta-site amyloid precursor protein-cleaving enzyme 1 inhibitor in nonhuman primates. J Pharmacol Exp Ther 2009, 328:131-140.

30. Georganopoulou DG, Chang L, Nam JM, Thaxton CS, Mufson EJ, Klein WL, Mirkin CA: Nanoparticle-based detection in cerebral spinal fluid of a soluble pathogenic biomarker for Alzheimer's disease. Proc Natl Acad Sci USA 2005, 102:2273-2276.
31. Zetterberg $\mathrm{H}$ : Update on amyloid-beta homeostasis markers for sporadic Alzheimer's disease. Scand J Clin Lab Invest 2009, 69:18-21.

32. Fukumoto H, Tokuda T, Kasai T, Ishigami N, Hidaka H, Kondo M, Allsop D, Nakagawa M: High-molecular-weight \{beta\}-amyloid oligomers are elevated in cerebrospinal fluid of Alzheimer patients. FASEB J 2010, 24:2716-2726.

33. Lannfelt L, Blennow K, Zetterberg H, Batsman S, Ames D, Harrison J, Masters CL, Targum S, Bush Al, Murdoch R, Wilson J, Ritchie CW; PBT2-201-EURO study group: Safety, efficacy, and biomarker findings of PBT2 in targeting Abeta as a modifying therapy for Alzheimer's disease: a phase lla, double-blind, randomised, placebo-controlled trial. Lancet Neurol 2008, 7:779-786.

34. Kadir A, Andreasen N, Almkvist O, Wall A, Forsberg A, Engler H, Hagman G, Larksater M, Winblad B, Zetterberg H, Blennow K, Långström B, Nordberg A: Effect of phenserine treatment on brain functional activity and amyloid in Alzheimer's disease. Ann Neurol 2008, 63:621-631.

35. Gilman S, Koller M, Black RS, Jenkins L, Griffith SG, Fox NC, Eisner L, Kirby L, Rovira MB, Forette F, Orgogozo JM; AN1792(QS-21)-201 Study Team: Clinical effects of Abeta immunization (AN1792) in patients with AD in an interrupted trial. Neurology 2005, 64:1553-1562.

36. Fleisher AS, Raman R, Siemers ER, Becerra L, Clark CM, Dean RA, Farlow MR, Galvin JE, Peskind ER, Quinn JF, Sherzai A, Sowell BB, Aisen PS, Thal LJ: Phase 2 safety trial targeting amyloid beta production with a gamma-secretase inhibitor in Alzheimer disease. Arch Neurol 2008, 65:1031-1038.

37. Bateman RJ, Siemers ER, Mawuenyega KG, Wen G, Browning KR, Sigurdson WC, Yarasheski KE, Friedrich SW, Demattos RB, May PC, Paul SM, Holtzman DM: A gamma-secretase inhibitor decreases amyloid-beta production in the central nervous system. Ann Neurol 2009, 66:48-54.

38. Portelius E, Price E, Brinkmalm G, Stiteler M, Olsson M, Persson R, WestmanBrinkmalm A, Zetterberg H, Simon AJ, Blennow K: A novel pathway for amyloid precursor protein processing. Neurobiol Aging $2009 \mathrm{Jul} 13$. [Epub ahead of print].

39. Portelius E, Dean RA, Gustavsson MK, Andreasson U, Zetterberg H, Siemers E, Blennow K: A novel Abeta isoform pattern in CSF reflects gammasecretase inhibition in Alzheimer disease. Alzheimers Res Ther 2010, 2:7.

40. Zetterberg H, Hietala MA, Jonsson M, Andreasen N, Styrud E, Karlsson I, Edman A, Popa C, Rasulzada A, Wahlund LO, Mehta PD, Rosengren L, Blennow K, Wallin A: Neurochemical aftermath of amateur boxing. Arch Neurol 2006, 63:1277-1280.

41. Glodzik L, De Santi S, Rich KE, Brys M, Pirraglia E, Mistur R, Switalski R, Moscon $L$, Sadowski M, Zetterberg H, Blennow K, de Leon MJ: Effects of memantine on cerebrospinal fluid biomarkers of neurofibrillary pathology. J Alzheimers Dis 2009, 18:509-513.

42. Degerman Gunnarsson M, Kilander L, Basun H, Lannfelt L: Reduction of phosphorylated tau during memantine treatment of Alzheimer's disease. Dement Geriatr Cogn Disord 2007, 24:247-252.

43. Deshmane SL, Kremlev S, Amini S, Sawaya BE: Monocyte chemoattractant protein-1 (MCP-1): an overview. J Interferon Cytokine Res 2009, 29:313-326.

44. Barone R, Sotgiu S, Musumeci S: Plasma chitotriosidase in health and pathology. Clin Lab 2007, 53:321-333.

45. Galimberti D, Schoonenboom N, Scheltens P, Fenoglio C, Bouwman F, Venturelli E, Guidi I, Blankenstein MA, Bresolin N, Scarpini E: Intrathecal chemokine synthesis in mild cognitive impairment and Alzheimer disease. Arch Neurol 2006, 63:538-543.

46. Tarkowski E, Issa R, Sjogren M, Wallin A, Blennow K, Tarkowski A, Kumar P: Increased intrathecal levels of the angiogenic factors VEGF and TGF-beta in Alzheimer's disease and vascular dementia. Neurobiol Aging 2002, 23:237-243.

47. Zetterberg $H$, Andreasen N, Blennow K: Increased cerebrospinal fluid levels of transforming growth factor-beta1 in Alzheimer's disease. Neurosci Lett 2004, 367:194-196.

48. Swardfager W, Lanctot K, Rothenburg L, Wong A, Cappell J, Herrmann N: A meta-analysis of cytokines in Alzheimer's disease. Biol Psychiatry 2010, 68:930-941.

49. Szekely CA, Zandi PP: Non-steroidal anti-inflammatory drugs and Alzheimer's disease: the epidemiological evidence. CNS Neurol Disord Drug Targets 2010, 9:132-139.

50. Sano M: Tarenflurbil: mechanisms and myths. Arch Neurol 2010, 67:750-752

doi:10.1186/alzrt56

Cite this article as: Zetterberg $\mathrm{H}$, et al.: Use of theragnostic markers to select drugs for phase II/III trials for Alzheimer disease. Alzheimer's Research \&

Therapy 2010, 2:32. 